\title{
Star Wars, una galaxia muy muy cercana: Un mito moderno y su construcción social
}

\author{
José Marco Segura Jaubert ${ }^{1}$ \\ Mitzi Magallón Delgado²
}

Recibido en 17 de octubre de 2016, aceptado el 15 de noviembre de 2016

\begin{abstract}
Resumen
A través de siete apartados se analiza la cronología de Star Wars, el contexto histórico-social que la determina y cómo se evidencia en la saga. También por qué se puede considerar Star Wars como un mito moderno y cómo refleja el viaje del héroe. Son estudiados aspectos religiosos que gira alrededor del concepto de la Fuerza, los aprendizajes biopedagógicos, la interculturalidad manifiesta en la saga y los elementos que ésta posee para que se desarrolle un nuevo camino espiritual llamado jedismo.

Palabras clave

Star Wars, mito, religión, biopedagogía, interculturalidad, jedismo.

Abstract

Through seven sections the chronology of Star Wars, the historical and social context that determines it and how is evident in the saga are analyzed. Also in which way Star Wars is a modern myth and how the hero's journey is reflected. Eeligious aspects that revolves around the concept of the Force, the biopedagogy learning, interculturalism manifested in the saga and the elements that this series of films has to develop a new spiritual path called jedism are studied.
\end{abstract}

Keywords

Star Wars, myth, religion, biopedagogy, intercultural, jedism.

1. Costarricense, máster en Literatura Clásica y filólogo, Universidad Nacional de Costa Rica. jm23jaubertair@hotmail.com.

2. Costarricense, psicóloga y doctora en Educación, Escuela Neuropsiquiátrica Infantil, Costa Rica. mitzimd@gmail.com. 
52 Star Wars, una galaxia muy muy cercana: Un mito moderno y su construcción social. José Marco Segura Jaubert, Mitzi Magallón Delgado.

\section{Cronología de la Saga}

Para entender la compleja trama que caracteriza la saga Star Wars es necesaria la cronología en que se desarrolla este universo, compuesta por siete episodios estrenados hasta ahora, y dos más confirmados a estrenarse en 2017 y 2019. El orden de aparición de los episodios es el siguiente: En 1977 sale la película original de Star Wars, posteriormente denominada Episodio IV: Una Nueva Esperanza; en 1980 llega a las pantallas de todo el mundo, el Episodio V: El Imperio Contraataca; en 1983 se exhibe el Episodio VI al que se denomina El Regreso del Jedi. Más tarde, en 1997, estos episodios fueron reestrenados en los cines luego de que fueran digitalmente corregidos y mejorados en imagen y sonido y agregadas nuevas escenas.

Durante 1999 se exhibe el Episodio I: La Amenaza Fantasma; en el año 2002 llega a la gran pantalla el Episodio II: El Ataque de los Clones. En el 2005 las precuelas se cierran, con la exhibición del Episodio III: La Venganza de los Sith y, finalmente, en el 2015 sale el Episodio VII: El Despertar de la Fuerza. Para diciembre del 2017 está prevista la exhibición del Episodio VIII y, para finalizar la saga, en el 2019 se estrenará el Episodio IX.

Más allá de las películas, Star Wars dio cabida a la creación del Universo Expandido (UE), una colección de materiales que cuentan el origen de las historias de dicho universo, que se desarrolla a través de novelas, cómics, videojuegos, series de televisión y otros medios ${ }^{3}$. El Universo Expandido nunca fue considerado canónico por LucasFilm. Incluso en el 2012, al Disney comprar la franquicia, declara que todo el UE publicado, hasta ese entonces, no sería tomado en cuenta para la nueva trilogía (episodios VII-VIII-IX). El Universo Expandido se empieza a llamar Leyendas y se considera una línea temporal alternativa a la oficial ${ }^{4}$. Ello recuerda, en gran medida, a los evangelios apócrifos en relación a los sinópticos aceptados por la Iglesia Católica.

En la cronología de la saga se toma como punto de referencia la destrucción de la primera Estrella de la Muerte en la Batalla de Yavin. Así, ABY se refiere a Antes de la Batalla de Yavin, y DBY, se refiere a Después de la Batalla de Yavin, otro paralelismo con la línea aceptada por Occidente con el antes y después de Cristo.

En las películas solo se observa un atisbo de dos de las eras de la cronología, sin embargo tanto estas dos como el resto, están ampliamente desarrolladas en el Universo Expandido 5 :

- Era de la Antigua República (25000 ABY - 1000 ABY)

- Era del Alzamiento del Imperio (1000 ABY - 0 DBY)

3. Sin contar con las películas, sus adaptaciones escritas y radiofónicas.

4. Paralelamente surgen otras líneas de tiempo, no reconocidas oficialmente.

5. Star Wars página oficial, http://www.starwars.com/ (consultada el 2 de septiembre de 2016). 
- Era de la Rebelión (0 DBY - 5 DBY)

- Era de la Nueva República (5 DBY - 25 DBY)

- Era de la Nueva Orden Jedi (25 DBY - 40 DBY)

- Era del Legado (40 DBY - ?)

La Era de la Nueva República, en especial, es el periodo más detallado en el UE, mientras que la era de la Antigua República es de los periodos más apreciados por los creadores y fans, porque narra el origen de la República como se conoce en los films. El Episodio VII transcurre, según la cronología alternativa, en lo que sería la Era de la Nueva Orden Jedi, aproximadamente 30 años DBY.

\section{Contexto histórico de Star Wars}

Star Wars permite la reflexión sobre conflictos morales, políticos, ideológicos e históricos de la humanidad. Ella es el reflejo de contextos históricos y sociales que han imperado en nuestro planeta, y además presenta referentes mitológicos y literarios, sin olvidar la influencia de corrientes espirituales como el New Age o religiones como el budismo, que constituyen el caldo de cultivo que alimenta la saga, y que el cineasta George Lucas ${ }^{6}$ coloca en una galaxia muy muy lejana, donde el espectador puede tomar distancia y no sentirse abrumado para realizar, a través de los episodios, un recorrido por la historia de la humanidad.

El primer referente es quizás la historia de conformación de los Estados Unidos, a través del espíritu épico del western ${ }^{7}$, su consolidación como federación, la unión de los distintos estados y, finalmente, su transformación en una república con tintes imperialistas.

Otras influencias destacadas son los rescoldos de la guerra de Vietnam que había dividido al pueblo de los Estados Unidos, y la renuncia del expresidente Richard Nixon ${ }^{8}$ por el caso Watergate ${ }^{9}$, las negociaciones Thatcher-Reagan, los conflictos con Medio Oriente, la guerra de Irak, el gobierno de George Bush, y el inicio de la globalización entre otros.

6. Cineasta nacido en Modesto, California, el 14 de mayo de 1944. Creador de la saga de Indiana Jones y American Graffiti y las compañías Lucasfilm Limited, LucasArts Entertainment Company, Lucas Digital Ltd., entre otras.

7. Películas del viejo oeste estadounidense. Cinematográficamente se fija el mito y la estética del salvaje Oeste, con la película Río Grande de John Ford, considerada la película clásica de este género. 8. Expresidente de Estados Unidos (1913-1944), único en el cargo que renuncia durante su mandato que se extiende durante cinco años (1969-1974). Se le señala por traer en 1973, la crisis del petróleo, el racionamiento de la gasolina y las revelaciones públicas sobre el caso Watergate.

9. Escándalo político que tiene lugar en junio de 1972 en Estados Unidos, que se genera debido al robo de documentos en el complejo de oficinas Watergate en Washington D.C., sede del Partido Demócrata estadounidense. El Presidente Nixon intenta encubrir a los culpables, mas no tiene éxito; los más altos mandos de la Casa Blanca estaban implicados en una amplia red de espionaje y sabotaje contra adversarios políticos, hecho que es negado por el presidente y que lo obliga a demitir de su cargo el 9 de agosto de 1974. Gerald Ford le concede el perdón presidencial, lo que le evita ir a la cárcel. 
La relación entre los planetas que pueblan la galaxia, es el reflejo de la diversidad de ecosistemas que existen en la Tierra y su compleja trama de interrelaciones. Se observa, por ejemplo, la presencia de razas con diversa evolución técnica y cultural que logran entrelazarse a través de la tecnología y los viajes hiperespaciales, que dan su adhesión a una forma de organización social, la República o el Imperio, configurándose así los dos bandos que están en constante lucha. Esta diversidad es reforzada, a su vez, por la visión de Estados/Planetas que se unen en el Senado Galáctico, similar a la Asamblea General de las Naciones Unidas (ONU); no por casualidad Coruscant, capital de la República, donde yace el Senado, tiene cierta semejanza física a New York.

Igualmente, en el universo de Lucas, se encuentran planetas que se pueden denominar de primer mundo, los cuales se ubican hacia el centro de la galaxia, tales como Coruscant, Alderaan, Naboo y Hosnian Prime, así como una serie de planetas periféricos, que, por estar en zonas alejadas de la galaxia, logran mantenerse al margen del conflicto principal República/Imperio, como es el caso de Tatooine ${ }^{10}$. Tatooine es un planeta pequeño y pobre donde la República no tiene injerencia, y que se encuentra controlado por Hutts, familia de gánster galácticos. Es tal el dominio ejercido por estas figuras que los dactarios ${ }^{11}$, dinero empleado en la República, no son válidos en este planeta marginal, tal y como se observa en el Episodio I (1999) cuando Qui-Gon Jinn ${ }^{12}$ intenta negociar con Watto ${ }^{13}$, por unas partes que necesitan para restaurar la nave en que los jedi ${ }^{14}$ y la Reina Amidala ${ }^{15}$ se dirigen a Coruscant:
Watto: ¿Cómo piensa pagar todo esto, ah?
Quin-Gon Jinn: Tengo en mi poder 20 mil dactarios.
Watto: Solo dactarios. La República no tiene crédito aquí.
Necesito algo más real.

Al igual que en nuestro planeta, en el universo de Lucas se observa la existencia de impuestos a las rutas comerciales por parte de la Federación de Comercio, la cual realiza un bloqueo económico sobre el planeta Naboo, similar al bloqueo económico que Estados Unidos tiene sobre Cuba.

Torres García $(2015,36)$ señala parte de este recorrido entre la República y el Imperio:

\footnotetext{
10. Los jedis aprovechan la marginalidad de este planeta para esconder ahí al pequeño Luke.

11. Moneda que se usa en las principales relaciones comerciales. Posteriormente, en época imperial, la moneda oficial son los créditos.

12. Jedi y maestro de Obi-Wan Kenobi, enviado a Naboo por el Consejo Jedi para solucionar el bloqueo comercial.

13. Comerciante de la zona, que tiene de esclavos a Anakin y a su madre Shmi Skywalker.

14. Guerreros-sacerdotes que mantienen la justicia y la paz en la galaxia.

15. Reina de Naboo, futura senadora y esposa de Anakin Skywalker.
} 
Es más, sirve perfectamente a ese relato al crear dos marcos diferenciados: libertad y tiranía. La idea de una democracia que desaparece en tiempos de crisis y que desemboca en un sistema autoritario, como ocurre con la formación del imperio galáctico que domina la galaxia bajo el mando de Palpatine y su lugarteniente Darth Vader, tiene un claro reflejo en la historia, como señala el propio Lucas en los comentarios a una de las entregas de la saga. Y el director cita tres ejemplos: Julio César, Napoleón y Hitler. Al igual que ocurría en Roma, la república que Lucas muestra en el episodio I, La Amenaza Fantasma (1999), está gobernada por un Senado y se encuentra inmersa en una crisis que es aprovechada por el senador Palpatine, cuyo nombre, como indica el libro Star Wars and History (Nancy R. Reagin y Janice Lied), recuerda mucho al del monte Palatino, la más céntrica de las siete colinas de Roma y uno de los lugares más significativos de la época antigua de la ciudad, desde donde se domina el foro y donde se encontraban muchos de los palacios, entre ellos la residencia del primer emperador, Augusto.

Más de mil ochocientos años después de la transición al imperio que se inicia con la acumulación de poder en la figura dictatorial de Julio César, primero y de su protegido César Augusto, después, Bonaparte se hizo con el gobierno de Francia y comenzó una época de expansión y control absoluto. Adolf Hitler manipuló las instituciones democráticas alemanas en un contexto de crisis política, económica y social para hacerse con el poder en Alemania, proclamarse Führer y establecer el führerprinzip o “principio"... J.J. Abrams, director de El despertar de la Fuerza, última entrega de la saga, señaló recientemente que la idea de "La Primera Orden" - la organización que lucha contra la resistencia y que se basa en los restos del Imperio-, surgió en una conversación en la que los participantes trataron de imaginar qué habría ocurrido si los nazis se hubiesen reunido en Argentina y hubieran comenzado a operar de nuevo.

En la saga está presente el conflicto bélico como reflejo de lo que se denomina guerras asimétricas ${ }^{16}$, protagonizada por la lucha entre los rebeldes y las fuerzas imperiales. En este conflicto se presentan acciones de espionaje: los rebeldes obtienen los planos de la Estrella de la Muerte; en La venganza de los Sith se observa cómo Anakin Skywalker ${ }^{17}$ es inducido a convertirse en doble agente, por un lado el Consejo Jedi le solicita que vigile al senador Palpatine, y por otro lado éste le pide informes de las acciones que lleva a cabo dicho Consejo.

También se muestra el uso de fuerzas especiales, como la creación del ejército de clones, que en un principio se hizo para resguardar la República; la utilización de droides como R2-D2 y C-3PO, que son personajes importantes principalmente en los episodios IV-V-VI, y BB8 en el episodio VII. Además, se presentan armas

16. Insurgencia/contrainsurgencia y crimen/daño colateral.

17. Personaje central de la saga Star Wars, héroe y villano de este universo. Padre de Luke, que posteriormente se transforma en Darth Vader. 
de destrucción masivas como las dos Death Star ${ }^{18}$ y la Star Killer, que destruyen distintos planetas y que no dejan de ser paralelos de las bombas atómicas lanzadas por los aliados en Hiroshima y Nagasaki durante la Segunda Guerra Mundial.

La lucha entre la República, representante de la democracia, y el Imperio, que simboliza el totalitarismo, es expuesta a través del relato histórico en los episodios I-II-III, donde se muestra una compleja trama política que ejemplifica cómo la democracia se autodestruye a través de la corrupción y el descrédito. En el Episodio III (2005), en una conversación entre Anakin y Padmé, el jedi le dice a su esposa que: “Paz y democracia son palabras prostituidas". En este mismo episodio, el senador Palpatine finge su propio secuestro para crear caos y fomentar el temor, y con ello, logra convencer al Senado de la necesidad de crear un ejército que proteja a la República.

Los sistemas adheridos al Senado renuncian a las libertades individuales debido al miedo, entonces miran el sistema totalitario como la tabla de salvación. En los episodios IV-V-VI el Emperador Palpatine utiliza el miedo como su principal arma, y la Estrella de la Muerte es el medio para mantener dicha amenaza, como indica el Gobernador Tarkin: "El miedo mantendrá el orden en los sistemas locales, el miedo a esta estación de combate". La política del miedo justifica que se utilice la tortura para obtener información, práctica que utiliza Darth Vader $^{19}$ al inicio del Episodio IV y que, posteriormente, Kylo Ren ${ }^{20}$ emplea en el Episodio VII.

En los episodios IV-V-VI, la democracia queda en el pasado y se convierte en la utopía a alcanzar. El Imperio es icónicamente asociado con el nazismo, lo cual se observa en la similitud que tienen los uniformes de las fuerzas imperiales con los del ejército nazi y en la forma del casco que posee Darth Vader. De igual manera puede apreciarse en varias escenas donde el orden, el rígido control y la deshumanización del ejército imperial, se homologan con las tropas de la SS del Tercer Reich. Además se aprecia un paralelismo ideológico presente tanto en Star Wars como en el ejército alemán: Lucas llama a un grupo de soldados imperiales tropas de asalto o stormtroopers, y el senador Palpatine es elegido presidente del Senado, se autodenomina emperador y elimina a todos sus adversarios, similar a lo que hace Hitler en Alemania; ambos elementos constituyen claras reminiscencias del fascismo nazi.

De esta manera el rescate de la libertad queda en manos de una minoría; la Rebelión, que simboliza la fuerza del más débil, Teseo contra el Minotauro, situación que se presenta a lo largo de la saga. En el Episodio VII el Imperio da

18. Solamente la primera Death Star llega a destruir el planeta Alderaan. La segunda es destruida antes de que pueda realizar un proceso semejante.

19. Anakin Skywalker.

20. Villano y Sith, hijo de Han Solo y la General Leia Organa. 
paso a la Primera Orden, que tiene similitudes con el gobierno de Corea del Norte, a decir de Torres (2015). Nuevamente la galaxia está bajo la amenaza y la opresión tal y como lo expresa Lord San Tekka²1: "La galaxia sufre nuevamente opresión... Viajé muy lejos y vi mucho como para ignorar toda la desesperación en la galaxia”. Esta opresión queda más clara con el discurso del General Hux ${ }^{22}$ en la base Star Killer en el Episodio VII (2015):

Hoy es el fin de la República. El de un régimen que consiente el desorden. En este momento en un sistema muy lejano, la Nueva República le miente a la galaxia... Mientras que secretamente apoya a la traición de la repugnante Resistencia ¡Esta máquina feroz, que han construido, sobre la que estamos, le pondrá fin al senado y a su preciada flota! ¡Los sistemas restantes se inclinarán ante la Primera Orden!

Por otro lado Star Wars, al ser una narración épica, reconceptualiza las principales historias que posee la humanidad. Como lo señala Torres García $(2015,38)$ :

Es una narración épica que enlaza en su concepción con la llíada o el ciclo artúrico, pero también deudora de otros referentes como la Epopeya de Gilgamesh, el Mahabharata y el Ramayana, o la propia Biblia; y que nos retrotrae al tipo de novelas de aventuras históricas del siglo XIX en la estela de Walter Scott o Rafael Sabatini a través de sus versiones cinematográficas. Una epopeya donde los héroes (según el modelo de Joseph Campbell y lord Raglan) son arquetipos (en la línea de Campbell, George Frazer y Carl Jung), en la que el drama y la gloria del protagonista, Anakin Skywalker, se corresponden con el desarrollo del tiempo histórico por el que discurren sus acciones en un mismo arco narrativo; una épica donde los personajes se sitúan en los márgenes de las funciones de los cuentos (en concordancia con Vladimir Propp y Bruno Bettelheim); que recogen las metáforas mitológicas sustentadas en la tesis de monomito (Campbell); que viven con la tragedia clásica incluyendo el descenso al reino de Hades; que siguen las líneas maestras de Shakespeare o Maquiavelo, sin obviar a Platón (sus guardianes de la República y reacción frente a la tiranía) o Santo Tomás, y cruzando el estoicismo con el tao o el zen pero sin dejar a un lado la faz nietzschiana en los $\operatorname{Sith}^{23}$ o una particular lectura de la exaltación individualista de Ayn Rand en la concepción de los rebeldes.

Lo hasta aquí descrito evidencia cómo lo que Lucas coloca en una galaxia muy muy lejana, toca las fibras más sensibles del acontecer histórico, que en realidad está ubicado en un universo muy muy cercano.

21. Miembro de la Resistencia escondido en el planeta Jakku. Posee información vital sobre el paradero de Luke Skywalker.

22. General de la Primera Orden, que mantiene recelos con Kylo Ren.

23. Figuras homologas a los jedi que controlan el lado oscuro de la Fuerza. 
58 Star Wars, una galaxia muy muy cercana: Un mito moderno y su construcción social. José Marco Segura Jaubert, Mitzi Magallón Delgado.

Ya establecido el ligamen entre Star Wars y la historia, conviene establecer por qué la saga creada por Lucas es un mito para la sociedad actual, tal y como lo fueron La Ilíada y La Odisea para los griegos.

\section{Star Wars como mito moderno}

Eliade (1991) indica que el mito cuenta una historia sagrada, que ha ocurrido en el tiempo primordial, el tiempo fabuloso de los "comienzos" o in illo tempore ${ }^{24}$, frase utilizada en las iglesias por los sacerdotes a la hora de narrar los acontecimientos bíblicos, o bien en los cuentos de hadas ${ }^{25}$. Star Wars se encuentra enmarcada dentro de este concepto de mito. Desde el epígrafe que se revela antes del inicio de cada episodio "Hace mucho tiempo en una galaxia muy, muy lejana...", Lucas introduce al espectador en un universo donde se hace referencia a un tiempo inmemorial. Se asemeja también al inicio de Las divertidas aventuras de Robin Hood, cuyo autor la historia esconde: "Hace cientos de años, los vikingos realizaron continuas campañas de conquista por toda Europa". ${ }^{26}$

Como se observa, en ninguno de estos casos aparece el tiempo cronológico, siempre es el tiempo mítico, el comienzo de las cosas.

Si se sigue a Eliade (1991), el mito cuenta cómo, por las gestas de seres sobrenaturales, una realidad ha venido a la existencia por ende describe las variadas $y$, muchas veces dramáticas, irrupciones de lo sagrado en el mundo. El mundo se fundamenta en esta irrupción de lo sagrado para ser como es. Entonces un mito cosmogónico ${ }^{27}$ es verdadero porque la existencia del mundo está ahí para probarlo; los mitos de la muerte son igual de verdaderos puesto que la mortalidad del ser humano así lo prueba y, si se ve de forma análoga, la historia de Star Wars es verdadera porque la existencia de las películas así lo prueban.

La historia relatada por Lucas entre los episodios I y VI aparece, ya mitificada, en la última entrega Star Wars VII El despertar de la Fuerza:

Finn: Aparentemente tiene un mapa que lleva directo a Luke Skywalker ${ }^{28}$. Y todos están detrás de él.

Rey: ¿Luke Skywalker? Creí que era un mito...

El personaje de Rey, heroína en esta entrega, refiere a Luke Skywalker como parte de una historia sagrada que había ocurrido mucho tiempo atrás, de la que

24. Frase en latín que significa "En aquel tiempo".

25. El conocido "Había una vez...”.

26. Anónimo. Las divertidas aventuras de Robin Hood (Buenos Aires: Ediciones Terramar, 2007$), 11$.

27. Son aquellos mitos que intentan explicar el origen del mundo.

28. Jedi de la Rebelión, hijo de Anakin Skywalker. 
incluso se duda que haya pasado. El trasfondo de este episodio es encontrar a la figura de Skywalker, es conectar, por así decirlo, a personajes como Rey, Finn ${ }^{29}$, Poe Dameron ${ }^{30}$ y Kylo Ren con ese pasado mítico, con esa historia sagrada y, analógicamente, se busca conectar a la generación de hoy con aquella historia que fue llevada al cine hace décadas; se busca, a fin de cuentas, introducir a las nuevas generaciones dentro del mismo proceso mitológico, dentro del mismo viaje del ser humano.

Esta conexión entre el presente y el pasado se ejemplifica claramente en el filme, cuando Rey y Finn a bordo del Halcón Milenario ${ }^{31}$ se encuentran con Han Solo ${ }^{32}$, quien advierte que lo que se creía que era una leyenda es realmente una historia sagrada, de la que él mismo dudaba en un inicio, pero que termina siendo cierta:

Rey: Los jedi eran reales...

Han Solo: Solía preguntarme eso mismo... pensaba que eran un montón de historias descabelladas... un poder mágico que une el bien y el mal... el lado oscuro y la luz... lo más extraño de todo es... que es cierto... La Fuerza... los jedi... todo sobre ellos. Todo es verdad.

Solo, conforme se desarrolla la trama de la saga, pasa de ser un descreído pirata a una persona que, ya con la edad, se da cuenta de la verdad: cuando el grupo se acerca al templo de Takodana ${ }^{33}$, él expresa una frase que advierte al espectador que el viaje dentro del mundo mágico acaba de iniciar: "Han: ¿Crees que fue suerte que Chewie ${ }^{34}$ y yo encontráramos el Halcón?”

Han Solo sabe lo que va a ocurrir si encontraba la nave de su propiedad que fue robada tiempo atrás: encontrar el Halcón supone la entrada al relato mítico. Solo adquiere, en cierta medida, un carácter profético ya que enseña a Rey y a Finn sobre el relato sagrado e, indudablemente, transporta al cinéfilo con su aparición al tiempo mítico y lo pone de cara a él; como lo expresa Henderson (2005, 124):

La saga Star Wars narra la historia intemporal del viaje de un héroe en pos de cumplir su destino y vencer a las fuerzas del mal. Se trata inequívocamente de un mito de finales del siglo XX.

29. Antiguo soldado de la Primera Orden que, posteriormente, se une a la Resistencia.

30. Piloto de la Resistencia enviado a Jakku para buscar información sobre Luke Skywalker.

31. Nave que aparece en la trilogía original de Star Wars (1977-1983), piloteada por Han Solo y Chewbacca que es clave en la destrucción de las dos Death Star construidas por el Imperio.

32. Personaje esencial en la trilogía original (1977-1983), capitán del Halcón Milenario, compañero sentimental de la Princesa Leia y padre de Ben Solo, mejor conocido como Kylo Ren.

33. Abrevadero dirigido por Maz Kanata, conocedora de la Fuerza sin ser jedi.

34. Chewi, es el diminutivo de Chewbacca, wookie copiloto del Halcón Milenario. 
60 Star Wars, una galaxia muy muy cercana: Un mito moderno y su construcción social. José Marco Segura Jaubert, Mitzi Magallón Delgado.

Se puede decir que La guerra de las galaxias ${ }^{35}$ es una historia antigua contada de manera novedosa. Como bien lo expresa Campbell, padre intelectual de Lucas, en la entrevista con Bill Moyers ${ }^{36}$, citado por Henderson $(2005,125)$ :

Moyers: Iba a decir que estos están creando nuevos mitos, pero me dices que no, cada mito que creamos hoy tienen algún punto de origen en nuestra experiencia pasada.

Campbell: Los temas básicos de los mitos son los mismos, y siempre han sido los mismos.

Con la idea de que los temas básicos de los mitos se repiten de generación en generación, se puede observar semejanzas entre diferentes relatos míticos a lo largo de la historia. Una de las semejanzas que tiene la mayoría de estos relatos es que en ellos existen los héroes, y Star Wars no es distinta en este sentido al presentar tres personajes en esta línea: Rey, Anakin Skywalker y el hijo de este último, Luke Skywalker, personaje cuyo viaje se analiza en el siguiente apartado.

\section{Star Wars y el viaje del héroe}

Pausanias ${ }^{37}$ indicaba en el pasaje 8.8.3 del libro VIII de la Descripción de Grecia que, pese a que en un inicio pensaba que los relatos antiguos no poseían ningún sentido, cerca de la zona de Arcadia cae en cuenta que éstos poseen verdades profundas y perdurables que se revelan de manera alegórica.

Dentro de los mitos, como se señala al final de la sección anterior, aparecen héroes. Los héroes son personajes especiales que cumplen una función salvadora o soteriológica para con su entorno. Se encuentran en un estrato especial entre los dioses y los seres humanos, son hijos normalmente de una mortal y un dios o viceversa, como ocurre con personajes de la talla de Orfeo, Perseo, Aquiles, Beowulf. Su nacimiento es de una forma distinta al resto de los mortales. El héroe suele poseer la espada ${ }^{38}$ y es, simbólicamente, identificado con el Sol ${ }^{39}$. El astro rey posee la dualidad Luz / Oscuridad y su desaparición en las aguas de Occidente está en relación con la muerte violenta de los héroes ${ }^{40}$. Posteriormente el Sol renace en Oriente, lo que se consideraba en la Antigüedad, como resurrección.

\footnotetext{
35. Nombre con que se conoce a la saga Star Wars en el mundo de habla hispana.

36. Nacido el 5 de junio de 1934, es periodista y comentarista político. Trabajó para la Casa Blanca durante la administración Johnson (1965-1967).

37. Fue un geógrafo e historiador griego del siglo II de esta era. Se cree que era nativo de la región de Libia, ubicada en Asia Menor, probablemente de Magnesia del Sipilo, y que realizó varios viajes por las zonas de Grecia, Macedonia, Italia, entre otras. Su obra se considera una fuente valiosa de información histórica acerca de la topografía, los monumentos y los cultos de la antigua Grecia.

38. Arma asemejada al fuego, light saber o sable de luz en Star Wars.

39. Para la simbología del Sol ver: Eduardo Cirlot. 2007. Diccionario de Símbolos (Madrid: Editorial Ciruela): 420-23.

40. Como ocurre con Orfeo o Jesús.
} 
Los héroes aparecen en el animé japonés, en la literatura o en el cine, casos como el de Gokú en la serie animada Dragon Ball, Batman, Superman, Naruto, Harry Potter, Aragorn en El Señor de los Anillos, Optimus Prime en Transformers, son algunos de los numerosos ejemplos de este basto mundo.

De acuerdo a Henderson (2005), cuando Joseph Campbell sostenía que todas las historias míticas se fundamentan en un fondo común de imágenes y símbolos, se refería al trabajo que realiza Carl Jung con su teoría de los arquetipos. Jung indica que cierto tipo de impulsos o instintos psicológicos se manifiestan a través de fantasías, y revelan su presencia mediante temas simbólicos. Esto, de la misma manera, puede representarse en forma de personajes: princesas ${ }^{41}$, caballeros $^{42}$, dragones ${ }^{43}$ o magos $^{44}$, que ayudan u obstaculizan la aventura heroica.

El viaje del héroe no solo se da en el plano físico, sino también, en el plano espiritual, refleja no solo su viaje por parajes desconocidos, sino que expone también su viaje interno, de conocimiento de sí mismo.

El héroe pasa de la completa ignorancia de sí mismo, al conocimiento total de sus miedos y virtudes a través de la experiencia. Por ello se considera el viaje heroico como un proceso iniciático como el que ocurría en las culturas primitivas. El viaje heroico es un viaje a través del inconsciente del héroe y, analógicamente, es un recorrido por el inconsciente de las personas que, a fin de cuentas, buscan el conocimiento en las pruebas que enfrentan los guerreros.

Se conciben varias fases dentro de la aventura heroica donde el héroe se auto descubre. En todas las historias estos pasos se cumplen a cabalidad, pero se tienen que dar cuatro esencialmente: llamado a la aventura, pruebas y auxiliares, huida y elixir. Se analizan en esta sección, las diferentes etapas del viaje heroico de Luke Skywalker ${ }^{45}$ en la trilogía original de Star Wars.

\section{a. Star Wars IV: Una nueva esperanza}

- Mundo ordinario: En esta primera etapa se hace referencia al espacio físico donde habita el héroe antes de que la aventura inicie. En los mitos los héroes suelen venir de los extremos del espectro social y existencial: son hijos de reyes o nobles, pero por algún azar del destino en relación con su propio nacimiento ${ }^{46}$, los héroes son enviados lejos a una tierra donde crece

41. La Princesa Leia Organa, Pocahontas.

42. Sir Lancelot y los Caballeros de la Mesa Redonda.

43. Fafner, Smaug, Shen Long, Fújur.

44. Yoda, Merlín, Obi-Wan Kenobi, Gandalf.

45. Se ha escogido a este personaje debido a que su viaje heroico está expuesto de forma completa; su padre cae al lado oscuro y el viaje de Rey se encuentra en desarrollo.

46. La profecía o la maldición como le ocurre a Edipo Rey. 
pobre y en el anonimato, incluso en muchos casos son huérfanos ${ }^{47}$. Ello ocurre con Luke Skywalker: su padre, el jedi Anakin Skywalker, simboliza al padre eterno y es considerado el elegido, su madre es la Reina Amidala y, por ende, su linaje es sagrado o de sangre real, mas por las circunstancias que lo rodean, tiene que crecer como un pobre campesino en las zonas alejadas a Mos Eisley, puerto espacial del desértico planeta Tatooine.

- El llamado a la aventura: En esta fase al héroe se le presenta una crisis o un desafío. Luke Skywalker es un joven inocente y carente de cualquier experiencia sobre el mundo que le rodea. El llamado a la aventura se da de dos maneras en los héroes: $a$. De forma interior: que surge en la psique del personaje: Skywalker desea saber sobre su padre; y b. De forma exterior: es la más común en los mitos, sucede cuando el destino tienta al héroe ${ }^{48}$ : con el héroe galáctico ocurre con la llegada de los androides R2-D2 y C-3PO, que vienen con un mensaje de una princesa en peligro que necesita ser rescatada. Este motivo de rescatar a una mujer de estirpe real, aparece en una de las dos obras insignias de la cultura griega, La llíada de Homero, con la famosa Helena de Troya.

- Los Guardianes en el Umbral: Antes de su aventura iniciática Luke ya debe sortear dos obstáculos:

a. Los tusken raiders ${ }^{49}$, que buscan adueñarse de las pertenencias que posee Luke en su speeder al salir en busca de R2-D2 ${ }^{50}$, androide que quiere localizar al jedi Obi-Wan Kenobi ${ }^{51}$. Los tusken raiders representan la lucha externa o física que debe afrontar Skywalker.

b. Los guardianes en el umbral son, o malévolos como los tusken raiders, o benignos y protectores. El tío Owen ${ }^{52}$ y la tía Beru ${ }^{53}$ cumplen estos roles benignos. El tío Owen representa la lucha interna del futuro jedi, su primer obstáculo para trascender, ya que Owen no quiere que el joven se una a la Rebelión. Owen es una figura paterna y el rol que desarrolla con el héroe, es un breve reflejo de lo que experimentará el joven campesino con su padre.

- Encuentro con el mentor o ayuda sobrenatural: El héroe necesita ayuda especial para iniciar su búsqueda y ella aparece ejemplificada en la figura de un maestro que lo informa y entrena para su desafío. En el ciclo artúrico se puede ver esta figura en el mago Merlín, también Gandalf en El Señor de los Anillos o el señor Myagi en Karate Kid. Dentro del universo de Star Wars este arquetipo del antiguo sabio está personificado por Obi-Wan

47. El caso de Moisés en el Antiguo Testamento.

48. Como ocurre con Odiseo cuando sabe que debe ir a Troya, o Eneas cuando tiene que ir a fundar Roma.

49. Moradores de las arenas.

50. Otro de los personajes centrales de las películas, compañero inseparable del androide de protocolo C-3PO.

51. Sabio maestro jedi, que luchó en las Clone Wars junto a Anakin Skywalker.

52. Hermano político de Anakin Skywalker. Obi-Wan Kenobi deja a su cargo la crianza de Luke al caer la República.

53. Esposa del tío Owen. 
Kenobi, caballero jedi retirado en la soledad de Tatooine. Kenobi le da un objetivo a Luke en su caminar: ser un caballero jedi como lo fue su padre Anakin. Kenobi hace entrega a Skywalker de un talismán: la espada de luz que perteneció a su padre. Dentro de los mitos la espada ${ }^{54}$ es símbolo de legitimidad, y es la herencia de padres a hijos en forma de arma poderosa.

- Cruce del primer umbral: El héroe abandona el mundo que conoce para entrar en el mundo especial o mágico. Con el héroe de la Rebelión ocurre de forma abrupta, al darse cuenta que sus tíos han muerto a manos del Imperio, decide seguir el consejo de su mentor y marcharse; piensa que debe recalar en el planeta Alderaan. Pero, al igual que Odiseo en el intento de volver a Ítaca, su travesía dura mucho tiempo.

- Los compañeros del héroe: El héroe enfrenta pruebas, encuentra aliados y lucha con enemigos, de forma que aprende las reglas del mundo especial. La figura del compañero del héroe viene desde la Epopeya de Gilgamesh en la figura de Enkidu, amigo y rival de Gilgamesh; Jasón, en Grecia, tiene a los Argonautas. Skywalker y Ben Kenobi encuentran al pirata espacial Han Solo y a su ayudante el wookie Chewbacca. Su lugar de encuentro es en la cantina espacial de Mos Eisley, que supone un primer descenso al inframundo. Dentro de la psicología del héroe este lugar representa regiones de su subconsciente, donde deja atrás el yo consciente rutinario y se relaciona con sus instintos.

- La dimensión mística: Todos los mitos tienen en común que, en cierto momento, el héroe debe tener un cambio de consciencia, para Skywalker ello ocurre al empezar el entrenamiento para volverse jedi y aprender los caminos la Fuerza. Dicho conocimiento va más allá de lo que el héroe conoce, deja atrás las leyes físicas que lo tienen atado y abandona los prejuicios mentales. Para usar el arma del padre, el joven jedi ha de hallar fuerza interior: una paz interna.

- El laberinto y el rescate de la princesa: En los mitos antiguos son recurrentes las historias de héroes que rescatan a princesas de las mazmorras de castillos dominados por caballeros oscuros. Estos castillos son similares a los laberintos que en los mitos representan siempre el paso a lo desconocido ${ }^{55}$. Skywalker debe rescatar a la Princesa Leia $^{56}$ de las garras del Imperio y del infame Darth Vader ${ }^{57}$, quien tiene custodiada a la princesa en los pasadizos de la Death Star.

- Perder al guía: Pese a que en estas historias el héroe triunfa sobre el mal, es posible que este último tome la vida de uno de los compañeros de viaje del héroe. En Star Wars Darth Vader elimina a Ben Kenobi, guía del héroe y su antiguo maestro jedi.

\footnotetext{
54. Dentro del ciclo artúrico aparece la espada Excálibur.

55. Teseo y el laberinto del Minotauro.

56. Hermana gemela de Luke Skywalker y líder de la Rebelión.

57. Vader es la perfecta figura oscura, mientras que Leia, vista desde los arquetipos jungianos, es considerada el anima que personifica los aspectos femeninos de la psique masculina de Luke (animus); se debe tener en cuenta que Leia es hermana de Luke.
} 
- Hazañas heroicas y cazadores de dragones: El héroe está listo para una prueba mayor, donde se enfrenta a sí mismo en estancias más desafiantes. La Death Star funge dentro de este estadio mítico como el dragón al que se debe derrotar. Tanto el héroe como el dragón poseen la misma fuerza, ya que, de otro modo, no existiría posibilidad de éxito. El hijo de Anakin dispara torpedos de protones en una pequeña abertura bajo la plataforma principal de la Death Star, que genera una reacción en cadena que la destruye. Skywalker vence al dragón, cual Sigfrido a Fafner o David a Goliath. Esto supone un nuevo nivel de iniciación dentro de la aventura heroica y obtiene sus primeras recompensas. ${ }^{58}$

\section{b. Star Wars V: El Imperio Contraataca}

Después de la destrucción de la Death Star, Luke Skywalker se traslada junto al resto de la Rebelión al congelado planeta Hoth. Su entrenamiento para convertirse en jedi sigue su curso y nuevas dificultades aparecen en su camino.

- Camino de adversidades: el héroe galáctico está a la mitad de su camino de autodescubrimiento, ahí comienza un descenso interno donde busca conquistar el poder de las tinieblas. Dicha fase también la describe Dante en la Divina Comedia: “En mitad de nuestra vida, me desvié del camino recto y desperté en un oscuro bosque" 59 .

- La cacería: Este concepto se repite varias veces dentro del Episodio V. Depredadores merodean, atrapan y logran tragar incluso a los héroes de la Rebelión; los cazarrecompensas ${ }^{60}$ se encargan de este papel. En estas pruebas sobresalen las virtudes del héroe que, de una u otra manera, logra escaparse y dar con sus objetivos. En estos avatares el héroe entiende que debe seguir su proceso y busca dar el próximo paso; Skywalker comprende que debe ir al sistema Dagobah, a aprender de Yoda, el anciano maestro jedi que lo pone a prueba tanto de forma física como mental.

- $\quad$ El bosque sagrado: En Dagobah Skywalker ingresa en un terreno vedado donde sufre una transformación. La gran cantidad de árboles presentes en la geografía del planeta permiten una homologación con los bosques sagrados que existían en la Antigüedad, como lo salían tener los Druidas o aquellos iniciados dentro del culto de la diosa Deméter o Ártemis en Grecia. El bosque simboliza cambio y sabiduría, donde muchas veces hay hechiceros o sacerdotes que enseñan ese poder ${ }^{61}$; paralelamente estos bosques pueden simbolizar el subconsciente, emociones ocultas o recuerdos oscuros que esperan ser revelados.

- En el vientre de la ballena: El camino a través del umbral hacia una

58. José Marco Segura Jaubert, “El viaje del héroe de Luke Skywalker en Star Wars: Parte 1 de 3: Una nueva esperanza (A New Hope)," Breaking Away, marzo 2014, 24-26.

59. Dante Alighieri, The Inferno (Nueva York: New American Library, 1982), 28.

60. Entre ellos IG-88, Boosk, Dengar y el enigmático Boba Fett.

61. En el caso de Star Wars, es el maestro Yoda. 
transformación espiritual e intelectual, requiere de una muerte simbólica para renacer; la coraza del héroe debe ser agrietada para obtener la esencia que lleva dentro. El viaje heroico comprende una separación del mundo, para que el héroe regrese a éste de una manera distinta, más completa y consciente de $s^{6}{ }^{62}$. Ello se observa en El Imperio Contraataca al héroe descender a la cueva del espejo en Dagobah, de donde busca renacer, como Jonás en la ballena, mas no lo logra. Skywalker aniquila al monstruo que aparece en la cueva, representado en la figura de Darth Vader que, al ser vencido, muestra el rostro, y no es más que el propio Luke Skywalker. El monstruo no debe ser aniquilado por el héroe ya que es parte de él, no debe ser eliminado sino aceptado. ${ }^{63}$

- Sacrificio: Hacia la parte final de El Imperio Contraataca sucede el primer enfrentamiento entre Darth Vader y Skywalker: lucha entre padre e hijo. Un ejemplo similar se encuentra en la mitología griega, al Cronos devorar a sus propios hijos en busca de Zeus que, finalmente, corta los testículos de su padre y toma su lugar en el Olimpo. En esta ocasión el aprendiz de jedi se cree más fuerte que su rival, y subestima a su padre quien lo mutila hacia el final de la pelea; otro suceso que aparece en la mitología: el héroe o dios mutilado ${ }^{64}$. Allí mismo Vader, aparte de revelar que es el padre del joven, tienta a su hijo con el poder del universo, similar a la tentación que sufre Cristo en el desierto. Luego de la batalla el héroe se tira al abismo, realiza una catábasis ${ }^{65}$, señal inequívoca de que el héroe ha dejado la inocencia, ha sufrido la muerte simbólica para renacer en el tercer acto.

\section{c. Star Wars VI: El regreso del jedi}

En el Episodio VI de Star Wars las luchas internas desarrolladas por Skywalker en el Episodio $\mathrm{V}$ son llevadas al plano exterior, con el fin de dar una conclusión clara y definitiva al recorrido heroico. Después de la lucha con Darth Vader en Cloud City, Luke retoma la travesía que lo lleva a toparse nuevamente con su padre a bordo de la nueva Death Star. En esta parte final del recorrido heroico se presentan estas fases:

- El regreso del héroe: En el comienzo de la película Skywalker regresa a su planeta natal Tatooine, ya es un hombre distinto, consciente de sus virtudes y de sus debilidades, ha dejado la infancia y ha dado paso a la madurez y al entendimiento. El aprendiz de jedi ${ }^{66}$ busca transmitir sus conocimientos

62. Tal y como ocurre con Juan Salvador Gaviota después de ser desterrado por la bandada de gaviotas a la que pertenece.

63. Este motivo también aparece en la Historia Interminable con el personaje de Atreyu en una las pruebas que debe enfrentar tras resolver el enigma de la Esfinge. En el animé Naruto, el protagonista se encuentra con su "otro yo" en la catarata mientras entrena con Killer Bee.

64. Orfeo fue desmembrado por las Bacantes, como Dioniso por los Titanes, o el propio Jesús al ser crucificado.

65. Descenso al inframundo.

66. El personaje de Skywalker puede encontrar un paralelo con los hobbits en su regreso a La Comarca después de destruir el anillo en el Monte del Destino; los hobbits regresan cambiados y 
mas no es fácil, su primera prueba se da al enfrentar a Jabba The Hutt al rescatar a su amigo Han Solo.

- Resurrección y combate con el monstruo: Aunque ya la Fuerza está arraigada en Skywalker, el héroe no deja de sufrir vicisitudes y es capturado en el Palacio de Jabba, y debe idear un plan para escapar de las garras del gánster y rescatar a sus amigos. Al enfrentarse al Sarlacc ${ }^{67}$, Skywalker es obligado a mantenerse en equilibrio al borde de una plataforma, de igual forma que lo hizo contra Darth Vader en Cloud City, mas Luke en esta etapa ya es fuerte y triunfa, se encuentra listo física y mentalmente para el duelo final contra su padre y el Imperio.

- El resurgimiento del Mal: La regeneración no solo es cosa del Bien, el Mal también se levanta, como la Hidra en la mitología griega que lucha con Heracles. En Star Wars esta fase se pone en la palestra con la construcción de la segunda Death Star y la aparición del Emperador Palpatine, que representa la esencia del monstruo que es el Imperio Galáctico: todo ego, sin espíritu, encerrado en un castillo de odio y agresión. El único que puede penetrar ese castillo es el que porta la chispa del fuego divino, el héroe cuyo corazón y espíritu ya están integrados: Luke Skywalker.

- Descenso al inframundo: De igual forma que sucede en el Episodio V, Luke sabe que debe tomar un camino diferente al de sus amigos para devolver a su padre de las tinieblas; para que Darth Vader pueda redimir sus actos. Así Skywalker inicia un periplo por la segunda Death Star, etapa que representa otro descenso al inconsciente ${ }^{68}$. El Emperador es ahora el monstruo que habita en el laberinto, es el que tienta al héroe y le ofrece el puesto que ocupa su padre. La batalla en el interior de Skywalker se intensifica, incluso vence a su padre por medio del odio, mas al ver en lo que se puede convertir, rechaza el ofrecimiento y es atacado por el Emperador.

- La reconciliación con el padre: Cuando Palpatine ataca al jedi, el hijo de Anakin se vuelve hacia su padre en busca de ayuda, ya que se encuentra al borde de la muerte. El momento de reconciliación entre el padre y el hijo es un arquetipo que aparece en muchas culturas, como ocurre con los indios navajo donde los Guerreros Gemelos salen en busca de su padre: el Sol. Se cuenta en este mito que el Sol hace pasar por terribles tormentos a sus hijos, y cuando ya está satisfecho los admite como sus vástagos. En el interior de Darth Vader / Anakin Skywalker, residen todas las potencialidades vitales: las de héroe y las de salvador $y$, como todo dios o héroe, posee la coincidencia de los opuestos ${ }^{69}$. Además el héroe debe encontrar otra potencialidad dentro de sí, la de ser el niño que no puede completar por si solo la tarea: “Luke Skywalker: Padre, por favor, ayúdame”.

deben enfrentar, nuevamente, a las fuerzas oscuras del mago Saruman.

67. Monstruo que es alimentado con prisioneros para entretenimiento de Jabba The Hutt.

68. Otros ejemplos: el descenso de Jesús a los infiernos tras la crucifixión, o el descenso de Heracles al traer a Teseo del Hades.

69. Coincidentia Oppositorum. Término que se utiliza para indicar que se poseen los opuestos, lo bueno y lo malo, lo positivo y lo negativo, lo que atrae y lo que repele, lo masculino y lo femenino. 
- Darth Vader hace caso a su hijo y deja la máscara oscura que tuvo durante años, Anakin Skywalker ha vuelto, se ha transformado por su hijo. Así una figura trágica hace su aparición, el viaje heroico solo es expuesto en una mínima potencia, es una especie de ángel caído que acaba por mostrar lo que en el fondo era.

- Caen las máscaras: Un tema expuesto en toda la saga, es la caída de los disfraces y la muestra de la verdadera esencia que se oculta tras ellos. Es importante recordar que cuando los mitos eran puestos en escena en la Antigüedad, los actores llevaban máscaras. Luke por fin logra ver el verdadero rostro de su padre, Anakin deja de lado la máscara de Darth Vader, símbolo incuestionable de la oscuridad. El rostro del hombre redimido es amorfo, carente de rasgos que lo definan, nadie puede desarrollar humanidad si se sirve a un sistema inhumano que lo aleja de su yo interior. Cabe resaltar como antecedente de esta idea, que cuando los rayos del Emperador alcanzan a Vader, se observa su calavera a través del casco. Es un anuncio de la humanidad que renace en él y que atraviesa su traje ${ }^{70}$. El antiguo señor oscuro de Sith muere al saber que su hijo tenía razón sobre él.

- Victoria final: Luke rinde tributo a su padre, al incinerarlo como un héroe sobre una pira refleja su potencialidad última. Igual a Hércules quien asciende a los cielos como dios después de pasar por la pira. La sabiduría, la compasión, el santo y el héroe guerrero residen ahora en Skywalker, como dice Campbell (2006, 147-148):

El héroe... asciende hasta la fuente del poder. Su rostro es también el de su padre, ahora comprende, y los dos están en paz... ya que para el hijo que por fin ha conocido al padre, las agonías del calvario han pasado; el mundo ha dejado de ser un valle de lágrimas para convertirse en una perpetua y benefactora manifestación de la Presencia.

Al dejar claras las conexiones que existen entre los diferentes mitos antiguos, conviene que en la próxima sección se revise la relación de La guerra de las galaxias con el mundo religioso, pese a que se observa en este apartado que la línea que divide al mito del mundo religioso, muchas veces es tan delgada como inexistente. Como lo decía Campbell (2001) la mitología era como las personas llamaban a la religión de otros.

\section{Star Wars y la divinidad: ¿Es la Fuerza un paralelo de Dios?}

Más allá de los efectos especiales y las espectaculares panorámicas que ofrece la saga de Lucas, es el concepto de la Fuerza, cómo se domina y qué acciones se ejecutan con ella, lo que mueve todo lo que sucede en la galaxia. Antes de comentar un poco más sobre el tema, conviene que se deje claro qué es la 
68 Star Wars, una galaxia muy muy cercana: Un mito moderno y su construcción social. José Marco Segura Jaubert, Mitzi Magallón Delgado.

Fuerza. Para ello se toman dos definiciones expresadas por los jedi Obi-Wan Kenobi y Yoda, en los episodios IV y $\mathrm{V}$ respectivamente:

Luke Skywalker: ¿La Fuerza?

Obi-Wan Kenobi: La Fuerza es un campo de energía creado por todas las cosas vivas, nos rodea y nos penetra, nos une como galaxia.

Luke Skywalker: No puedo... Es muy grande...

Yoda: No el tamaño importa... Mírame ¿por mi estatura me juzgas, huh? Pues no deberías, porque mi aliada es la Fuerza y una poderosa aliada es, de la vida es la creadora, crecer la hace, su energía nos rodea a todos y nos une, luminosos seres somos, no esta cruda materia. Debes sentir la Fuerza a tu alrededor, aquí, entre tú y yo, y el árbol y la roca... en todas partes... incluso entre la tierra y la nave.

Como se nota en ambos pasajes, la Fuerza es un campo de energía místico que rodea y penetra tanto a los personajes de la saga como a todo lo que está alrededor. Recuerda, en cierta medida y con la distancia del caso, a lo que expresa Jesús en el Evangelio de Tomás (1999, 93):

Jesús dijo: (...) Llegad a un madero. Yo estoy allí. Levantad la piedra y me encontraréis allí.

¿Es, entonces, la Fuerza un paralelo de Dios dentro del contexto cristiano? Pues sí se encuentran algunas semejanzas:

- Ambos crean vida.

- Los dos conceptos poseen omnipresencia en todas las cosas.

- $\quad$ El poder de Dios y la Fuerza son utilizados por personajes o personas para ganar batallas ${ }^{71}$.

- Tanto en los filmes como en la vida cotidiana, existen templos donde se imparte el conocimiento de los conceptos aquí comparados.

Mas existen diferencias que no permiten homologar la Fuerza con el concepto de Dios:

- La Fuerza es usada tanto por el bando de la luz (Jedi), como por el bando de la Oscuridad (Sith), el poder de Dios es solo usado por el bien.

- La Fuerza en sí no es una divinidad, Dios sí lo es.

- Mediante la Fuerza se puede viajar al futuro y al pasado, la divinidad cristiana no permite eso.

- Dios todo lo ve y todo lo sabe, y no se hace mención de ello en la Fuerza.

- Existe una división tripartita en el cristianismo de Padre, Hijo y Espíritu

71. Los jedi utilizan la Fuerza para vencer tanto a los separatistas como al Imperio. Constantino utiliza el símbolo de la Cruz para vencer, en la Batalla del Puente Milvio, contra las fuerzas de Majencio en el siglo IV d.C. 
Santo, la Fuerza, como tal, es una.

- George Lucas no afirma que la Fuerza sea una homologación de Dios, sino lo que busca es despertar la espiritualidad en la gente de hoy, como se desprende de la respuesta que le da Lucas a Moyers:

Moyers: ¿Es la Fuerza Dios?

Lucas: Puse la Fuerza dentro de las películas para tratar de despertar un cierto tipo de espiritualidad en la gente joven... Más personas creen en Dios que en cualquier sistema religioso particular... quiero decir... la verdadera pregunta es preguntar la pregunta... porque si tienes el suficiente interés en los misterios de la vida... preguntar las preguntas ¿Existe un dios o no existe un dios? Eso es lo peor que puede pasar a mi entender... preguntarle a alguien si existe un dios y que te diga que no lo sabe ¿sabes? Pienso que se debería tener una opinión sobre ello.

Moyers: ¿Y tienes una opinión o aún la estás buscando?

Lucas: Oh, pienso que existe un dios... la pregunta es ¿qué es ese dios? ¿o qué sabemos acerca de ese dios? Es de lo que no estoy seguro... Si hay algo que sé sobre la vida y... sobre la naturaleza de la raza humana... Es que la raza humana cree siempre saberlo todo...

(...)

Moyers: Una de las cosas que dicen los críticos es que Star Wars ha sido tan popular con los jóvenes es porque es religión sin ataduras... que es una base muy delgada para la teología...

Lucas: El hecho de que sea una base muy delgada para la teología es por lo que me resisto a llamar a la Fuerza Dios... Cuando la película se estrenó casi todas las religiones la usaron como ejemplo de su religión y tuvimos la capacidad de relacionarnos con la gente joven... y relacionarnos con las historias... específicamente de La Biblia... El Corán... La Torá... entonces si (Star Wars) es una herramienta para hacer que las viejas historias sean nuevas y relacionarlas a la gente joven... eso era lo que quería lograr ${ }^{72}$.

Al dejar claro que la Fuerza no es un paralelo de Dios, sino una base delgada para la teología, se puede decir que realmente Star Wars es una posibilidad para conectarnos con nuestra historia y el misterio de la vida.

La saga, como expresa Lucas, no es profundamente religiosa, pero sí presenta aspectos que son comunes a todos, a saber:

Moyers: ¿Qué piensas del hecho de que tanta gente haya interpretado Star Wars como profundamente religiosa?

Lucas: -No miro Star Wars como algo profundamente religioso... Veo Star Wars como la toma de todos los problemas que la religión representa y que son

72. The Mythology of Star Wars, https://www.youtube.com/watch?v=YpiEk42_0_Q, (consultada 5 de febrero de 2015). 
expuestos en un constructo más moderno y accesible del que la gente puede apropiarse para aceptar el hecho de que existe un misterio más grande allá afuera (...) La religión es un contenedor para la fe. La fe es pegamento que nos une a todos como sociedad. Fe en nuestra cultura, nuestro mundo o a lo que sea que nos estemos aferrando. Es una parte muy importante... creo... que nos permite mantenernos estables... mantener el balance... ${ }^{73}$

El punto clave en Star Wars es lograr el balance, el equilibrio de las cosas, que todo converja en el universo. La visión de Lucas permite el acercamiento de cualquier tipo de religión, deja entrar al que desee, sin ataduras ni restricciones, busca despertar el interés de la humanidad en las historias que muchas veces, por los fundamentalismos existentes, pierden capacidad para encontrar nuevos adeptos. Entonces permite, con esta apertura, la interculturalidad y la enseñanza en todas las direcciones y ámbitos. En el siguiente apartado se analiza cómo la interculturalidad y la biopedagogía están presentes en el universo de George Lucas.

\section{Star Wars: interculturalidad y biopedagogía}

¿Qué aprendizajes se extraen de Star Wars? ¿Son estos realmente biopedagógicos?

Sin duda alguna son muchas las enseñanzas que deja esta saga, las cuales han sido tratadas en múltiples artículos y documentales que se han realizado. En esta sección se abordan estas interrogantes desde el modelo biopedagógico, para resaltar el proceso de aprendizaje presente en Star Wars.

El concepto de biopedagogía fue propuesto por Maturana y Varela (1990) para destacar que "se aprende en la vida y se vive aprendiendo", en una relación que es dinámica y creativa, presente en las personas y en las sociedades a partir de contextos concretos. La idea fundamental de estos autores es rescatar la increíble capacidad que tiene el ser humano para aprender, para transformarse y para recrear el mundo.

Como señala Capra $(1998,284)$, el desarrollo humano está siempre asociado al aprendizaje, el cual es el medio por el que el organismo se relaciona con el ambiente. En el caso de las personas:

... Comprende el lenguaje y el pensamiento abstracto y por tanto los símbolos y las representaciones. Pero el pensamiento abstracto es tan sólo una pequeña parte de la cognición humana y generalmente no constituye la base para nuestras decisiones y acciones cotidianas. Las decisiones humanas nunca son enteramente racionales, sino que están teñidas por las emociones. El pensamiento humano se halla siempre embebido en las sensaciones y procesos corporales que forman parte de la totalidad del espectro de la cognición.

73. The Mythology of Star Wars..., (consultada 5 de febrero de 2015). 
La situación expuesta en el párrafo anterior, se observa con claridad en la saga cuando se trata de manejar la Fuerza, ya que el aprendizaje principal de un jedi es, precisamente, lograr control sobre las emociones, como se observa en el pasaje de El Imperio Contrataca (1980), cuando Yoda instruye a Luke en los caminos de la Fuerza:

Yoda: La fortaleza de un jedi fluye de la Fuerza. Pero cuidado con el lado oscuro: Ira, temor, agresión de la Fuerza del lado oscuro son. Fácil fluyen rápidos a unirse en el combate. Si una vez tomas el sendero del lado oscuro para siempre dominará tu destino. Te consumirá al igual que al aprendiz de Obi-Wan.

Por el contrario los sith obtienen poder al liberar emociones como la ira. Ello queda claro en El Retorno del jedi (1983) cuando Luke intenta salvar a su padre, el Emperador Palpatine trata de inducirlo al lado oscuro, y le insiste en que se deje llevar por lo que siente: "Palpatine: Me invade tu rencor. Estoy indefenso, toma tu arma, fulmíname con esa furia atroz y tu jornada hacia el lado oscuro se habrá completado."

Por su parte el Episodio VII muestra el proceso de conversión de Kylo Ren, donde en varias escenas éste tiene dificultad para el manejo de las emociones; por ejemplo cuando es informado sobre el escape de BB8 y Finn, Ren arremete contra el panel de control y el soldado de la Primera Orden que comunica el mensaje, cuando intenta dominar la mente de Rey y es ella quien logra conocer su temor de no llegar a ser tan fuerte como Darth Vader, o cuando se desata su ira al darse cuenta que Rey ha escapado.

Maturana y Varela (1990) señalan que este aprendizaje no se realiza en forma individual, sino que se hace en compañía de otros. Se aprende en contextos y con la ayuda de nuestro entorno. De ahí que se diga que somos siendo, pues nuestra existencia lleva implícita la construcción de nuestra realidad, lo que implica un constante aprender de los significados que se construyen en conjunto, y en relación, con el ecosistema del que se forma parte.

Estos autores también aclaran que la construcción de significados no se produce únicamente a través de procesos cognitivos estimulados por nuestra capacidad de raciocinio, sino también estimulado, en gran medida, por las emociones internas; como bien lo señala Maturana $(1996,238)$ :

... no es la razón la que guía lo humano, es la emoción. Los desacuerdos nunca se resuelven desde la razón, se resuelven desde la cordura. No es cierto que los seres humanos somos seres racionales por excelencia, somos, al igual que el resto de los mamíferos, seres emocionales que usamos la razón para justificar u ocultar las emociones en las cuales se dan nuestras acciones. Esto no es una desvalorización de la razón, es una invitación a darnos cuenta de que somos 
en el entrelazamiento del razonar y el emocionar en el vivir cotidiano, y a hacernos responsables de nuestros deseos.

Maturana $(2001,23)$ enseña que el aprendizaje humano se da a través de la biología del amor, es decir, que el aprendizaje humano no solo se da a través de procesos cognitivos meramente racionales, sino también a partir de las emociones, ya que cuando se hablan, se implican, se evocan o se connotan emociones, donde la emoción básica por excelencia es el amor:

Por esto mismo mantengo que no hay acción humana sin una emoción que la funde como tal y la haga posible como acto. Por esto pienso también que para que un modo de vida basado en el estar juntos, en interacciones recurrentes en el plano de la sensualidad en que surge el lenguaje se diese, se requeriría de una emoción fundadora particular sin la cual ese modo de vida en la convivencia no sería posible. Tal emoción es el amor. El amor es la emoción que constituye el dominio de acción en que nuestras interrelaciones recurrentes con otros hacen al otro un legítimo otro en la convivencia.

Star Wars demuestra a lo largo de la saga cómo son las emociones las que guían el camino de los héroes. Anakin Skywalker es movido por el amor a su madre y a Padmé, y el dolor de perderlas es lo que lo empuja hacia el lado oscuro. Se presenta una escena en El ataque de los clones (2002), donde la República enfrenta a los separatistas en Geonosis: Obi-Wan Kenobi, Anakin y, ya para ese momento, la Senadora Amidala, se encuentran en persecución del Conde Dooku. Al ser atacada la nave donde viajan Padmé cae de ella, Anakin se desespera y solicita que la nave se detenga para rescatarla, aunque ello signifique perder de vista a uno de los líderes de los separatistas. Obi-Wan intenta que Anakin entre en razón:

\author{
Anakin: ¡Aterriza la nave! \\ Obi-Wan: Anakin no dejes que tus sentimientos personales interfieran. \\ Anakin: ¡No me importa! \\ ... \\ Anakin: ¡Aterriza la nave! \\ Obi-Wan: ¡No puedo con Dooku solo! ¡Si lo agarramos, podemos poner fin a la \\ guerra! ¡Tenemos trabajo que hacer! \\ Anakin: ¡No me importa, aterriza la nave! \\ Obi-Wan: ¡Serás expulsado de la orden jedi! \\ Anakin: ¡No la puedo dejar! \\ Obi-Wan: ¡Se razonable! ¿Qué crees que haría Padmé en tu lugar? \\ Anakin: Ella cumpliría su deber.
}

A lo largo de la saga Anakin, convertido en Darth Vader, es temido por su ira, se caracteriza por ser implacable tanto con la Rebelión como con los soldados del Imperio. Al final del Episodio VI es el amor a su hijo lo que logra redimirlo. 
En el caso de Luke Skywalker es el amor y la obediencia a su tío, lo que lo sostiene en la granja, y es el amor hacia el padre idealizado lo que lo lanza a la aventura. Es el amor hacia Leia, el que convierte al contrabandista Han Solo en héroe, y es ese mismo amor el que lo hace ir tras su hijo Kylo Ren para encontrar la muerte en el Episodio VII:

Han Solo: Salgamos de aquí conmigo y ven a casa... Te extrañamos.

Kylo Ren: Me estoy haciendo pedazos. Quiero liberarme de este sufrimiento. Sé lo que tengo que hacer, pero no sé si tengo la fortaleza ¿Me ayudarías?

Han Solo: Sí. En lo que sea.

Seguidamente Kylo Ren simula que le entrega el sable de luz a su padre, mas lo prende y con el mismo atraviesa el cuerpo de Solo, mientras lo mira a los ojos y le dice gracias.

En este mismo episodio, es el amor y la solidaridad lo que mueve a Finn a volver a la Star Killer para rescatar a Rey, a pesar de que había decidido viajar lo más lejos de la galaxia para dejar atrás su vida de stormtrooper. A lo largo de la saga es el amor, la solidaridad y la interdependencia, lo que alimenta el deseo de los héroes de acabar con las desigualdades y los abusos.

Otro aprendizaje significativo que nos deja Star Wars es la construcción de un universo interestelar, basado en la convivencia y la interdependencia, a partir del reconocimiento de todas las razas como legítimos otros, a decir de Maturana, en un verdadero ejemplo de interculturalidad, tal y como lo señala Lucas en la entrevista que le realiza Moyers ${ }^{74}$ :

Moyers: ¿Qué lecciones crees que toman de Star Wars en lugares como Malasia, Italia o América del Sur?

Lucas: Bueno... uno de los temas principales en los filmes es que muchos organismos se dan cuenta que tienen que vivir juntos... y tienen que vivir juntos para un bien mutuo... no solo los humanos... sino todos los seres vivos... todas las cosas de la galaxia son parte de un todo más grande.

Esta idea es reflejada en el siguiente diálogo del Episodio I La Amenaza Fantasma (1999), cuando el ejército de la Federación de Comercio invade Naboo:

Qui-Gon Jinn: El ejército de droides está por atacar a los naboo, debemos avisarles.

Rey Gungan: A mí no me gustan los naboo. Los naboo se creen muy inteligentes, creen que sus cerebros son demasiado grandes.

Obi Wan Kenobi: Una vez que los droides tomen control de la superficie, tomarán control de ustedes.

74. Ver nota 75. 
Rey Gungan: No creo eso...

Obi Wan Kenobi: Ustedes y los naboo forman un círculo simbiótico, lo que le pase a uno afectará al otro, debe entender esto.

A lo largo de la saga se presentan más de 56 razas que coexisten tanto durante la época de La República como la del Imperio. En su mayoría apuestan a un sistema republicano como la forma de organización social democrática, que permite la interdependencia y el reconocimiento del otro como legítimo otro. Sin embargo, esta convivencia no siempre es pacífica y armoniosa, pues también está presente la monarquía como se observa en el planeta $\mathrm{Naboo}^{75}$, y la tiranía representada por el Imperio que busca gobernar el orbe mediante el miedo.

La interdependencia que es expresada principalmente a través del lenguaje, es representada mediante actos comunicativos, donde los personajes pueden dialogar desde la lengua propia y ser perfectamente comprendidos por los otros. La convivencia en Star Wars implica el dominio de varios idiomas, inclusive el dialecto de algunos androides como R2-D2 y BB-8, o bien el apoyo en la tecnología, como por ejemplo el papel de C-3PO, robot de protocolo especializado en traducción, el cual resulta un verdadero apoyo para que los héroes cumplan sus misiones, como ocurre en El regreso del jedi donde, debido a su intervención, la Rebelión logra el apoyo de los Ewoks, habitantes de la luna de Endor, para atacar el enclave imperial que controla la Death Star. Así, la interculturalidad es llevada, también, al plano de la convivencia con la ciencia y la tecnología.

Esta saga puede verse como una mediación pedagógica que atraviesa la razón del espectador, para llegar a su emocionar a través del séptimo arte. El cine es considerado un acto social y cultural, que tiene la capacidad de trasmitir al espectador emociones complejas, llevarlo a la piel de multitud de personajes, así como de contextos y escenarios variados. En el caso de Star Wars, al pertenecer a la épica galáctica, logra no solo ilustrar el acontecer de realidades ocurridas en la sociedad actual, sino que posee la capacidad de trasladar al espectador a mundos y universos diversos, donde se incluye el mundo interior del propio ser humano. Aspecto que Lucas tiene claro, tal y como se refleja en la entrevista de Moyers:

Moyers: Un profesor que conozco me comenta que recientemente preguntó a sus alumnos de primer año cuántos de ellos habían visto los tres filmes de la trilogía y todos en la clase levantaron la mano y me dijo: Espero que Lucas sepa que enseña a toda una generación.

Lucas: Yo tengo la filosofía de que todos enseñamos... y todos enseñamos todos los días de nuestras vidas y... no necesariamente son nuestros sermones... he descubierto que a los muchachos no les gustan los sermones para nada... pero es

75. Planeta de donde proviene la Reina Amidala. 
realmente la manera en que vivimos nuestras vidas y lo que hacemos con ellas y la manera en que nos conducimos... entonces cuando hago las películas estoy muy consciente del hecho de que enseño a una escala más grande de lo que lo haría al ser solamente un padre de familia o alguien que camina por la vida, porque tengo este megáfono... todos en los medios tienen un gran megáfono con el que pueden alcanzar a muchos tipos de personas y cualquier cosa que hagan o digan o la manera en que se conduzcan o lo que sea que produzcan... tiene influencia y enseña algo a alguien... y yo trato de estar consciente de lo que sea que diga ${ }^{76}$.

Es el emocionar el que hace que cientos de jóvenes trasciendan su papel de simples espectadores, para convertirse en co-creadores de este universo, lo que da luz a lo que se conoce como el universo expandido de Star Wars ${ }^{77}$, al punto de hacer necesario la creación de un canon, una especie de historia oficial que permita a las productoras LucasFilm y Disney encuadrar y contextualizar la saga.

De igual manera los aspectos éticos y morales de Star Wars, que giran en torno a la lucha entre el bien y el mal por tratar de dominar la Fuerza, son llevados a la cotidianidad de algunos espectadores a través de cientos de historias paralelas en donde se construye la cronología de la saga, de cómics, de videojuegos y de foros. Esto llega a su máxima expresión con la aparición del jedismo, aspecto que se trata en el siguiente apartado.

\section{Star Wars, un camino a la espiritualidad: el jedismo}

Si bien en esta saga no se intenta brindar un profundo mensaje religioso, como el propio Lucas lo señala ${ }^{78}$, Star Wars plantea una serie de principios y valores espirituales, que tienen una clara influencia de filosofías budistas y de la religión judeocristiana, razón por la que en algunos países como Inglaterra y Estados Unidos, algunos de los seguidores de esta serie de películas intentan la legalización de lo que se ha llamado una nueva religión: el jedismo. En este apartado, se analizan los principios y valores que Lucas toma tanto de estas corrientes religiosas, para brindar a los jóvenes una reflexión que los conduzca a cuestionarse sobre la espiritualidad.

Este cuestionamiento lo plantea el cineasta a partir del concepto de la Fuerza ${ }^{79}$. De acuerdo a Ginés (2015) George Lucas diseña dicho concepto de esta forma:

76. The Mythology of Star Wars, https://www.youtube.com/watch?v=YpiEk42_O_Q, (consultada 5 de febrero de 2015).

77. Son historias paralelas en donde se construye la cronología de la saga mediante libros, cómics, videojuegos y foros.

78. Como se comenta en el apartado de religión.

79. Analizado en el apartado 3 de este artículo. 
Trabajé en una teoría general para la Fuerza y después jugué con ella; traté de tomar todas las religiones, mayores o minoritarias, actuales o primitivas, y quise encontrar una idea que todas tuviesen en común.

También se señala que la saga contiene un claro enfoque maniqueista, principalmente en la lucha del bien y el mal. Torres ${ }^{80}$, por ejemplo, explica que estos principios, o los jedi y los sith, son excluyentes, lo que provoca que a lo largo de las películas, sea necesario vencer a los sith para alcanzar la paz, el orden y el equilibrio, ya que los sith son los que producen el desequilibrio de la Fuerza:

El triunfo final de la luz sobre la oscuridad es una tesis cristiana, son los hijos de la luz los que vencen definitivamente a los de las tinieblas, y lo que hace Lucas es recuperar para siempre el ángel caído Anakin/Darth Vader.

No obstante, como lo señala Alonso Seoane $(2011,1)$, dentro de la filosofía budista, lo que se presenta es la lucha entre la luz y la oscuridad, principios fundamentales en el budismo:

Una de las simbologías más evidentes se visualiza en las luchas con espadas de luz (láser), que denota de la claridad de la mente y su sabiduría (iluminación), pero además hay numerosas influencias estéticas y filosóficas que son constantes a lo largo de todos los capítulos.

De esta lucha deviene el principio del Maestro-Aprendiz que está presente a lo largo de toda la saga. Por el lado de los jedi: Qui-Gon Jinn-Obi Wan Kenobi, Obi Wan Kenobi-Anakin Skywalker, Obi Wan Kenobi-Luke Skywalker, Yoda-Luke Skywalker. Y por lado oscuro: Darth Siddious-Darth Maul, Darth Siddious-Darth Tyrannus, Emperador Palpatine-Darth Vader, Snoke-Kylo Ren. Esta idea también encuentra asidero dentro de la tradición mística occidental, como por ejemplo en la figura de Merlín y Arturo.

La saga deja el mensaje implícito de que lo material no interesa, que lo verdaderamente importante es la espiritualidad. Tal y como lo expresa Yoda en el Episodio V: "Luminosos seres somos, no está cruda materia..."

Además esta idea está representada en el personaje de Han Solo, que en el Episodio IV inicia como un contrabandista movido por el dinero, a lo largo de los episodios sufre una transformación y en la última entrega, El Despertar de la Fuerza, es quien confirma a los jóvenes héroes ${ }^{81}$ la existencia de los jedi y su poder ${ }^{82}$.

80. Pablo J. Ginés, “¿Qué tipo de espiritualidad prima en el universo de Star Wars: la oriental o la judeocristiana?", http://www.religionenlibertad.com/que-tipo-de-espiritualidad-prima-en-eluniverso-de-star-wars-46818.htm (consultada el 15 de septiembre de 2016).

81. Rey y Finn.

82. Dentro de la serie de Las Guerras Clones (2008), que no se encuentran en las películas, Obi- 
Otro principio en la tradición budista es el reconocimiento de los pequeños budas tibetanos a edades tempranas. Como señala Alonso Seoane $(2011,4)$ :

Se trata de grandes maestros, llamados tulkus en budismo tibetano, cuya reencarnación es buscada para formarlos en la enseñanza hasta alcanzar un nivel de sabiduría superior. Esta es la base de la religión y de los altos cargos en el sistema político tradicional tibetano, puesto que se admite que la mente puede tener más "recuerdos" de vidas pasadas en la infancia, cuando todavía no está contaminada por las emociones y errores que se irán acumulando a lo largo de la vida.

En el Episodio I esto se observa cuando Qui-Gon Jinn encuentra a Anakin Skywalker; el jedi se lamenta de que el niño no viva dentro de los límites de la República, ya que hubiese sido más sencilla su detección. Posteriormente Skywalker es llevado ante el Consejo Jedi, para realizarle pruebas y determinar si posee las cualidades de un futuro guerrero jedi. El maestro Yoda confirma que el niño es el elegido, pero prevé un futuro incierto al sentir el miedo en los pensamientos del pequeño. A pesar de la advertencia el Consejo permite que Anakin sea entrenado. De igual forma en el Episodio $V$ se muestra como Yoda considera que Luke es demasiado mayor para ser entrenado como jedi, y duda de tener éxito en su entrenamiento.

Esto puede relacionarse también con el concepto judeocristiano del elegido; en el caso de los Jedi, esperan un elegido que devuelva el equilibrio a la Fuerza. Anakin Skywalker y luego su hijo, Luke Skywalker, constituyen dicha esperanza. Cabe resaltar que la figura del salvador también está presente, en la religiosidad griega y en muchas culturas indoeuropeas anteriores al cristianismo.

Alonso Seoane $(2001,2)$ señala que:

Las enseñanzas de Obi-Wan coinciden con una perspectiva del budismo mahayana, según la cual un verdadero maestro es aquel capaz de mostrar al discípulo que él mismo es el maestro. Esencialmente, le enseña a creer y confiar en su instinto. En algunas tradiciones budistas, el instinto es interpretado como una prueba de sabiduría.

El principal ejemplo de ello se observa en el Episodio IV: Una Nueva Esperanza, cuando Obi-Wan Kenobi insta a Luke a que no use los instrumentos de su nave, sino que, por el contrario, utilice la intuición durante el ataque a la primera Estrella de la Muerte. 
La capacidad que tienen los maestros jedi de comunicarse telepáticamente e insertar mensajes en la mente de las personas, se relaciona con la idea budista de que la mente del maestro y la del discípulo son idénticas; la principal función del maestro es introducir al alumno en la esencia de la mente, para que comprenda qué es y cómo funciona, hasta llegar al concepto de maestro interior cuando el discípulo se convierte en su propio maestro ${ }^{83}$. Esto puede observarse en varias escenas, donde los jedi controlan la mente de soldados imperiales y los hacen realizar acciones contra su voluntad, o en el Episodio VII cuando Rey controla la mente del soldado de la Primera Orden para que la deje en libertad.

Dominar la mente es la tarea fundamental del aprendizaje jedi; para ello la mente debe estar concentrada en el momento presente, tal y como se observa en el entrenamiento de Luke con Yoda, donde el anciano maestro enseña a Luke a usar la Fuerza mediante el dominio de sus pensamientos, y a tener fe en sí mismo. Gracias a estos valores los jedi logran desarrollar la concentración y la intuición. Por ejemplo en el Episodio $V$ esto se muestra cuando Luke intuye que Leia y Han Solo están en peligro, lo que denota que el joven empieza a desarrollar un nivel profundo de conciencia y un rápido progreso en el entrenamiento.

Un jedi debe tener control de su cuerpo físico y de sus emociones, esta es la idea fundamental en la saga. Ya lo expresa Yoda, nuevamente en El Imperio contrataca (1980): “Yoda: Por 800 años he enseñado a los jedi... Un jedi debe tener el compromiso más profundo, la mente más seria.”

El budismo enseña que emociones como el odio, la ira o los celos, son la causa del sufrimiento. Star Wars resalta el papel del odio y el miedo como el origen de la esclavitud de las pasiones humanas.

Alonso Seoane señala que otro valor fundamental del budismo presente en La guerra de las galaxias es la disciplina como medio de aprendizaje, y su control, como el camino a la iluminación. Yoda en el Episodio I (1999), ante los miedos que percibe en Anakin, explica que: "el miedo lleva a la ira, la ira al odio y el odio al sufrimiento”. En el Episodio V (1980) Kenobi le advierte a Luke que Darth Vader intentará obligarlo enfrentarse a él antes de que esté preparado, por eso debe terminar su entrenamiento o correr el riesgo de caer en el lado oscuro. Cuando comprende la insistencia de Luke por ayudar a sus amigos, le pide que no sienta odio, pues esta emoción puede conducirle a la oscuridad. Por esta razón en el Episodio VI (1983) Palpatine intenta llevar a Luke a las sombras, al despertar en él la ira y el miedo. Finalmente padre e hijo se ayudan al salvarse mutuamente y derrotar al Emperador. 
En el Episodio III (2005) Anakin acude a Yoda para consultarle sobre sus sueños premonitorios. El gran maestro le dice: "aprende a dejar ir todo aquello que temes perder". De esta forma el jedi le explica que la muerte es parte natural de la vida, y que si se deja vencer por el temor, entonces caerá en el lado oscuro, y es precisamente este temor el que lleva al héroe a su caída, cuando el Emperador Palpatine le ofrece enseñarle una técnica para revertir el curso de la vida y evitar, así, la muerte. En el Episodio VII se observa a los dos nuevos discípulos, Kylo Ren y Rey, enfrentarse mentalmente para controlar al otro, al final es Rey la que vence al intuir el miedo más profundo de Ren.

Otra enseñanza que señala Alonso Seoane (2011), es que los jedi Obi-Wan Kenobi y Yoda mueren de acuerdo con las enseñanzas budistas tibetanas, en donde los grandes maestros trascienden sin luchar, en meditación y sin dejar el cuerpo, lo cual, desde estas enseñanzas, representa el mayor grado de perfección que se puede alcanzar.

Otro principio importante que se evidencia en la saga es la importancia del amor y la compasión como camino hacia la realización; no por casualidad la heroína de los episodios I, II y III se llama Padmé, que en sánscrito significa loto. La palabra se compone de Pad o (Pe) que representa la sabiduría que purifica la ignorancia, y Me, que significa generosidad que purifica la avidez. En el budismo el loto simboliza la intención altruista de encontrar la sabiduría, el amor y la compasión $^{84}$. Igualmente estos valores están presentes en las batallas que se libran a lo largo de la saga, donde el triunfo se halla fundamentalmente en la cooperación y la compasión, presentes en los futuros soldados de la Rebelión, que luego conformarán la resistencia contra el Imperio.

Son estos principios y valores los que hacen que un grupo creciente de seguidores de la saga, intenten oficializar una religión llamada jedismo. Tal y como lo señala de Castella (2014), en el artículo digital para la BBC:

Todo comenzó como una broma a los expertos en estadística. En el censo realizado en 2001 en el Reino Unido se preguntó a la población por primera vez sobre sus creencias religiosas. Un 0,7\% de la población, 390.127 personas, se describieron como "Jedi", y en el resto del mundo cada vez, aumenta el número de seguidores.

Castella indica que para Beth Singler ${ }^{85}$, investigadora de la Facultad de Religión de la Universidad de Cambridge, las creencias jedi son una amalgama de principios tomados principalmente del budismo, aunque también pueden

84. María Jesús Alonso Seoane, "Un análisis de contenido sobe los elementos budistas de la Guerra de las Galaxias, "... 1-14.

85. Investigadora de la Facultad de Religión de la Universidad de Cambridge. Ver Tom de Castella "El Jedismo, la religión de los seguidores de la Guerra de las Galaxias," BBC Mundo, 26 de octubre de 2014, sección Noticias. 
80 Star Wars, una galaxia muy muy cercana: Un mito moderno y su construcción social. José Marco Segura Jaubert, Mitzi Magallón Delgado.

encontrarse influencias de principios del cristianismo, taoísmo y tradiciones samurái.

Tanto de Castella como Singler señalan que lo que comienza como ejercicio intelectual por parte de los seguidores de Star Wars, se ha convertido en un intento serio de crear un sistema de creencias coherente. Estiman que, actualmente en el Reino Unido entre el $0.4 \%$ al $0.7 \%$ de la población se considera adepta al jedismo, cifra similar a los cienciólogos en ese país y superior a los Testigos de Jehová en Nueva Zelanda. Un fenómeno similar se reporta en Australia, República Checa y México, lo que da a entender que la influencia de las películas y sus enseñanzas es global.

Star Wars es inspiración para la búsqueda espiritual de muchos de los espectadores. Como se indicó Lucas nunca tuvo la intención de crear una religión, y la mayoría de los seguidores del jedismo no lo ven como un gurú, e incluso ya se han apartado de los films; por ejemplo, en Estados Unidos, los seguidores de esta corriente espiritual se basan en tres pilares: foco, conocimiento y sabiduría, y afirman que lo que los guía es la misma filosofía que inspiró el film ${ }^{86}$.

Por su parte Patrick Day-Childs ${ }^{87}$ señala que ingresa en el jedismo a manera de broma, pero conforme comienza a reflexionar sobre los pilares espirituales de esta creencia, su entusiasmo se convierte en devoción: "Uso estos principios cada día de mi vida"; además le produce calma y lo mueve a ayudar sus semejantes. Otros seguidores afirman que buscan no obsesionarse con las cosas, desligarse de las pasiones excesivas, huir del materialismo y centrarse en la serenidad ${ }^{88}$.

Otra característica de este movimiento espiritual es que los seguidores no comparten un espacio físico, templo o centro de reuniones, el mismo se desarrolla a través de un gran número de foros en internet, a través de los cuales los seguidores tratan de encontrarse a sí mismos y tener un sentido de comunidad. El principal foro de los jedistas es, de acuerdo con Liliana Martínez ${ }^{89}$, la página web llamada Temple of The Jedi Order. Sin embargo, en el 2015, un grupo de universitarios en Turquía solicitó la creación de un Templo Jedi, petición que ha tenido réplicas en otras partes del país y que podría convertirse en un fenómeno de masas, como señala Martínez.

86. Tom de Castella "El Jedismo, la religión de los seguidores de la Guerra de las Galaxias," $B B C$ Mundo, 26 de octubre de 2014, sección Noticias.

87. Periodista y experto en videojuegos. Miembro del consejo directivo de la iglesia del jedismo en el Reino Unido. Ver Tom de Castella "El Jedismo...," BBC Mundo.

88. De Castella "El Jedismo...," $B B C$ Mundo, y Liliana Martínez "El jedismo, una religión in crescendo," La Razón, 22 de diciembre de 2015, sección Cultura.

89. Periodista del Diario digital la Razón.es. 
El jedismo tampoco tiene rituales o vestimentas similares a los personajes de las películas, por eso se puede afirmar que la guía que poseen son los principios a los que se adhieren. Kitchen ${ }^{90}$ ratifica que los seguidores son:

... Personas normales y que rara vez van disfrazados como en la película. De vez en cuando alguna túnica, no exenta de polémica en determinadas ocasiones. En 2008, Daniel Jones, un joven de 23 años que fundó la Iglesia del Jedismo junto a su hermano, fue expulsado de un supermercado al norte de Gales por negarse a quitarse ese atuendo por motivos religiosos, y en el 2010 un seguidor de los jedi fue expulsado de un centro de empleo en Essex por el mismo motivo, aunque después le pidieron perdón.

Fueron incidentes pacíficos, propios de una gente que no cree en la violencia ni en la dialéctica limitante de otras religiones. En su culto no existe el pecado ni un Papa como el de Roma. Tampoco tienen templos donde ir a adorar a un Dios.

Chryssides ${ }^{91}$ y Vernon ${ }^{92}$ comparan esta motivación con la que lleva a las personas a darle su adhesión a un partido político. Por su parte Walker ${ }^{93}$ considera que el jedismo busca que sus seguidores vivan más felices y sean altruistas. Algunos de sus preceptos son: emoción y no paz, conocimiento y no ignorancia, serenidad frente a la pasión, armonía frente al caos, fuerza sobre muerte.

La espiritualidad, a decir de Leonardo Boff ${ }^{94}$, que hace parte de las búsquedas humanas, está ligada a la necesidad de trascendencia que tiene el ser humano, que lo conduce a su propia transformación interior. Star Wars evoca esta necesidad de trascendencia y transformación, razón por la que se puede afirmar que se ha convertido en un camino hacia la espiritualidad para muchos de los fanáticos de la saga que hicieron suyos estos principios, e intentan incorporarlos a su cotidianidad a través de lo que se denomina en este artículo aprendizaje biopedagógico. Los seguidores del Templo de los Jedi tienen certeza de que los principios de la orden perdurarán, como Obi-Wan Kenobi le dice a Darth Vader en el Episodio IV: “Si me derribas, volveré aún más poderoso de lo que puedas imaginar". ${ }^{95}$ Dichos seguidores trascienden la pantalla del séptimo arte, para crear un fenómeno social que va in crescendo a nivel mundial, al encontrar en Star Wars el camino para su propia espiritualidad.

90. Michael Kitchen seguidor del jedismo. Mencionado en Martínez “El jedismo, una religión...,", La Razón.

91. Autor del libro El estudio de la religión. Mencionado en Tom de Castella "El Jedismo...," BBC Mundo.

92. Exsacerdote y psicoterapeuta. Mencionado en Tom de Castella "El Jedismo...," BBC Mundo.

93. Obispo anglicano de Manchester. Mencionado en Tom de Castella "El Jedismo...," BBC Mundo.

94. Teólogo brasileño galardonado con varios premios tanto en Brasil como en el exterior.

95. Martínez “El jedismo, una religión...,", La Razón. 
82 Star Wars, una galaxia muy muy cercana: Un mito moderno y su construcción social. José Marco Segura Jaubert, Mitzi Magallón Delgado.

\section{Conclusión}

Por medio de estos apartados se ha podido dar cuenta de las innegables conexiones que existen en Star Wars con diferentes aspectos de la historia mundial, la filosofía, el mito, la religión, la biopedagogía y la interculturalidad, hasta llegar a convertirse en un camino espiritual como lo muestra la aparición del jedismo. Más que volver a resaltar todo lo anteriormente dicho, conviene señalar que el deseo de realizar este análisis parte del hecho de querer enseñar que somos parte de la historia humana en sus múltiples facetas, que el viaje heroico es de todos los seres del planeta Tierra. Pero quizá la enseñanza más profunda es una que, por lo general, escapa a todos los análisis que se hacen a la saga: Star Wars, por un lado, revela la parte interior de todo lo que somos y cómo hemos vivido, pero por otro lado, es una gran metáfora de nuestra existencia en el cosmos que nos recuerda que hay que ser seres humanos; que en el fondo de nuestra mente sabemos que, a fin de cuentas somos polvo de estrellas y que pertenecemos a una galaxia muy lejana entre las tantas que se encuentran en el firmamento.

\section{Bibliografía}

Alonso Seaone, María Jesús. 2011. Un análisis de contenido sobe los elementos budistas de la Guerra de las Galaxias. Aposta revista de ciencias sociales 48 (Enero, Febrero y Marzo): 1-14.

Aligieri, Dante. 1982. The Inferno. New York: New American Library.

Anónimo. 2007. Las divertidas aventuras de Robin Hood. Argentina: Ediciones Terramar.

Anónimo. 1999. Textos gnósticos. Biblioteca de Nag Hammadi II. Evangelios, hechos, cartas. Madrid: Editorial Trotta.

Benítez Bolorinos, Manuel. 2016. Star Wars, un mito moderno. Diario Información, 27 mayo, sección Cultura.

Bermejo Barrera, Juan Carlos. 1988. Historia del Mundo Antiguo. Madrid: Editorial AKAL. Campbell, Joseph. 2001. Thou art that: Transforming the Religious Metaphor. California: New York Library.

2005. El héroe de las mil caras. México: Fondo de Cultura Económica.

Capra, Fritjof. 1998. La Trama de la Vida. Barcelona: Editorial Anagrama.

Cirlot, Juan Eduardo. 2007. Diccionario de Símbolos. Madrid: Ediciones Ciruela.

de Castella, Tom. 2014. El Jedismo, la religión de los seguidores de la Guerra de las Galaxias, BBC Mundo, 14 de octubre, sección Cultura.

Eliade, Mircea. 1991. Mito y realidad. Barcelona: Editorial Labor S.A.

Pablo J.Ginés, ¿Qué tipo de espiritualidad prima en el universo de Star Wars: la oriental o la judeocristiana?, http:/ /www.religionenlibertad.com/que-tipo-deespiritualidad-prima-en-el-universo-de-star-wars-46818.htm (consultada el 15 de septiembre de 2016).

Henderson, Mary. 2005. Star Wars: La magia del mito. Barcelona. Círculo Latino. 
Martínez, Liliana. 2015. El jedismo, una religión in crescendo, La Razón, 22 de diciembre, sección Cultura.

Maturana, Humberto y Francisco Varela. 1990. El Árbol del Conocimiento. Chile: Editorial Universitaria.

Maturana, Humberto. 1996. El Sentido de lo Humano. Chile: Editorial Dolmen, $8^{\circ}$ edición. 2001. Emociones y Lenguaje en Educación y Política. Chile: Editorial Dolme.

Pausanias. 1994. Descripción de Grecia. Volumen 3. Madrid: Gredos.

Segura Jaubert, José Marco. 2014. El viaje del héroe de Luke Skywalker en Star Wars: Parte 1 de 3: Una nueva esperanza (A New Hope). Breaking Away, marzo.

Star Wars página oficial, http:/ / www.starwars.com/ (consultada el 2 de septiembre de 2016). The Mythology of Star Wars, https://www.youtube.com/watch?v=YpiEk42_O_Q (consultada el 5 de febrero de 2015).

Torres García, Fernando. 2015. Star Wars: La saga nace en la historia. El mejor cóctel histórico-cultural del mundo. Clío: Revista de Historia, n. 172. 